\title{
Logistic tools for optimization of the regional distribution center
}

\author{
Elena Makovetskaya ${ }^{1, *}$ \\ ${ }^{1}$ Tyumen Industrial University, Volodarskogo str., 38, Tyumen, 625000, Russia
}

\begin{abstract}
The paper proposes the use of the integrated logistic approach, application of the cross-functional logistic coordination and integration in managing processes of the distribution center that promotes both to minimization of expenses and enhancing the effective functioning of the distribution center in the supply chain. The SMED analysis of logistic processes and Value Stream Mapping make it possible to identify inefficient operations and to reduce the duration of a logistics cycle. The researches of processes conducted by the author with the use of the logistic tools allowed revealing the reserves and making recommendations on how to enhance the effectiveness of the regional distribution center.
\end{abstract}

\section{Introduction}

In the conditions of market economy, the use of tools of logistics by economic entities is represented relevant as it promotes the forming of competitive advantages of the company.

According to D.J. Bowersox, V.I. Sergeeva, in modern business the significant changes, which are characterized by the fact that not the companies but supply chains compete among themselves, happen $[1,2]$.

The costs for performance of the logistic functions and operations make from $35 \%$ to $48 \%$ of all expenses of the company in the sphere of retail trade. In the structure of logistic expenses in various branches of industry of economically developed countries $20-40 \%$ are the share of inventory management, transportation costs represent $15-35 \%$, expenses on administrative and managerial functions represent 9-14\% [2].

The work of the modern distribution center is characterized by the increase in the number of logistic operations, the increasing complexity of logistic functions, multiproduct deliveries and shipments. JSC Tander (trading network "Magnit") includes 37 distribution centers, 36 motor transport enterprises, more than 18 thousand shops of different formats in 65 regions of Russia [3]. In 2017 the Tyumen Distribution Centre (TDC) was open. Its total area is more than 40 thousand sq.m. and it is one of the largest multifunctional logistics centers in the Tyumen region. TDC relates to the objects of class "A" and it is characterized by high level technical equipment and standardization [4]. The researches of logistic processes conducted in TDC showed that the storage facilities are used to their maximum limit and there are inefficient logistic processes. The question of finding the internal

${ }^{*}$ Corresponding author: Makov27EG@mail.ru 
reserves to optimize the logistic expenses at increasing intensity of streams and shipments without decreasing performance indicators of activity of Tyumen Distribution Centre is particularly acute for the company.

\section{Methods}

The general methodological principles of a research of a logistics system and processes of the distribution center include [5].

- The system approach, which is manifested in the consideration of all participants, elements of logistic processes as interconnected and interacting in a logistics system towards a common goal.

- The principle of total expenses is based on accounting of total logistics costs at management of material and related information, financial, service streams throughout all logistic chain. The minimum of the overall logistic costs is considered as one of the main in optimizing of logistics processes and systems.

- The principle of logistics coordination and integration consists in the achievement of the coordinated, integrated participation of all links of the logistics system (chain) in the management of material and related streams.

- The principle of modeling and information and computer support. Various models are used in the analysis and optimization of processes and elements in logistics systems: mathematical, economic-mathematical, graphic, imitating, etc.

- The principle of stability and adaptability. The logistics system has to work steadily at tolerances of parameters and factors of the environmental factors (for example, fluctuation of orders from shops, changes of conditions of deliveries of suppliers, etc.). The logistics system of the distribution center has to adapt to new conditions, changing intensity of logistic streams, loading of the equipment and other criteria of optimization at the considerable fluctuations of factors.

- The principle of a humanization of functions and technology solutions in logistics systems causes compliance of logistic processes to ecological, social requirements, etc.

The methodology of system approach and the above-mentioned principles were applied within the research of logistic processes of the distribution center.

Processing, the analysis of the statistical and logistic information connected with functioning of the distribution center was carried out by methods of mathematical statistics, calculation and analytical methods, forecasting methods $[6,7]$.

The functional logistic cycle is the basis of the integrated logistics and management of supply chains. Regardless of the complexity of logistics system in general, it is necessary to investigate a configuration of a separate logistic cycle for identification of the major interrelations and lines of control. Time intervals of the separate operations entering a functional logistic cycle can be random value and all cycle is the random value submitting to a certain law of distribution.

In a general view, the problem of optimization of duration of a functional logistic cycle can be presented $[8,9]$.

- for the average value of time of a functional logistic cycle $(\bar{T})$ :

$$
\bar{T}=\sum_{i=1}^{n} \bar{T}_{i} \rightarrow \min
$$

- $\quad$ for the standard deviation of the duration of separate operations of a logistic cycle $\left(a^{2} T\right)$ : 


$$
\alpha_{T}^{2}=\sum_{i=1}^{n} \alpha_{i}^{2}+2 \sum_{i \leq j} \eta_{i j} \alpha_{i} \alpha_{j} \rightarrow \min ,
$$

where $T_{i} \cdot a_{i}$ - the average value and the standard deviation of operation $i ; \eta_{i j}$ - correlation coefficient between operation $\mathrm{i}$ and operation $\mathrm{j}$ of the logistic cycle.

The probabilistic interpretation of a logistic cycle allows to determine its duration $T_{0}$ with the set probability.

$$
T_{0}=\bar{T}+x_{p} a_{T}
$$

where $x_{p}$ - the indicator of normal distribution corresponding to probability $P$.

The SMED analysis and Value Stream Mapping were tested by the author and are recommended for the application in the distribution center as the tools of the analysis of logistic processes $[10,11]$.

Value Stream Map (VSM) allows visualizing logistic process and revealing the losses of time increasing duration of logistic cycles. Stages of Value Stream Mapping are presented in figure 1 .

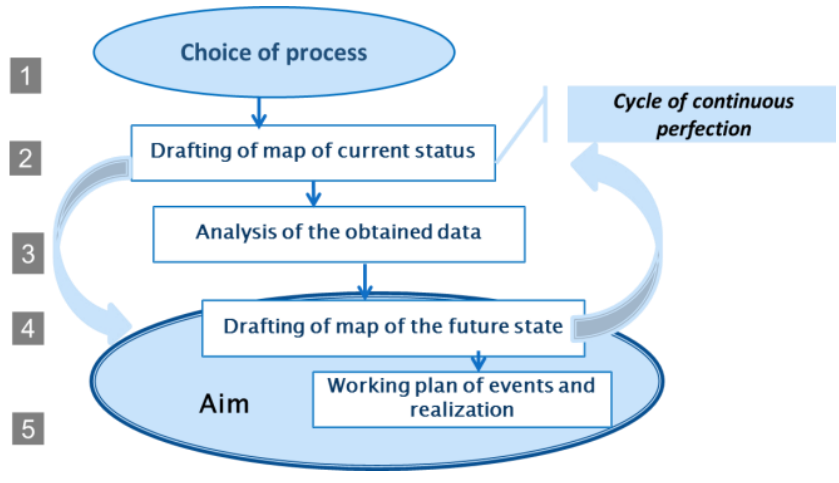

Fig. 1. Stages of Value Stream Mapping.

It is necessary to pass all stream from the beginning to the end for formation of understanding of borders of process and an essence of the studied operations prior to mapping. Measurements of time of each block of the chosen logistic process or operation are reflected on the current state VSM. It is necessary to structure the duration of operation for value added time (vat) and non-value added time (nvat). The number of participants in each block/operation are surely fixed in the monitoring process and the mapping of current state VSM. The problems and factors increasing time of the duration of operation, undermining the quality of goods or caused damage, wear of the equipment are also fixed. By results of measurements of time and their fixing in the current state VSM, the effectiveness coefficient of a stream is computed.

$$
\text { Kef }=\frac{\sum v a t}{\sum n v a t} \rightarrow \max
$$

The mapping of "future state" VCM of the process is directed to the elimination of sources of losses and idle times. The development of the actions has to be directed to the solution of the problem revealed by results of mapping which "delays" the process. Each action assumes the presence of the responsible official for realization, term of realization and the expected result. 


\section{Results and Discussion}

The researches of the logistic operations and processes in a zone of the main warehouse with use of the tools offered above by the author were conducted for the purpose of the identification of the bottlenecks in the logistics system and the optimization of the logistic processes of the Tyumen distribution center.

The duration of the logistic processes of the completion of the orders, shipments of goods to consumers in TDC directly depend on the process of acceptance of the transport returnable container. Logistic process includes the operations from the moment of the installation of the car under unloading from the returnable container, and finishing with conveyance of transport container to the zones of the completion of the orders or to the zone of repair and processing. The observations were carried out behind unloading more than 400 transport trucks, 87 thermoboxes and 112 thermal covers, only the operations on opening the gates were steadily carried out (figure 2).

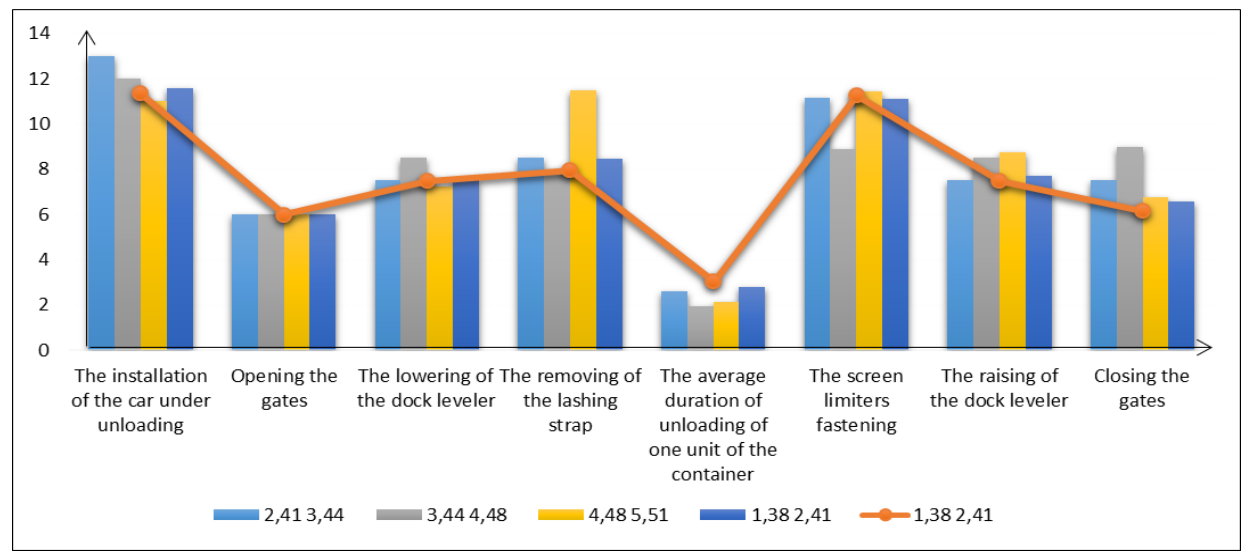

Fig. 2. The duration of the operations the acceptance area of the transport returnable container.

The following problems in TDC have been revealed as a result of the made observations and the analysis of logistic operations:

- the repeated check of internal contents of transport container increases the time of logistic cycle;

- there is no information on the expected receipt of container on DC (quantity, state);

- not sorted salvage in transport returnable container is led to the long acceptance;

- the congestion of the DC's zone of unloading returnable container.

Results of mapping of process of the completion of the order, the loss of time are presented in table 1 .

The effectiveness coefficient of process of the completion of the order varies from 0.69 to 0.83 .

Table 1. The analysis of the losses of time in the course of the completion.

\begin{tabular}{|c|c|c|c|c|c|c|c|}
\hline KO & $\begin{array}{l}\text { General } \\
\text { duration of } \\
\text { a task, sec. }\end{array}$ & $\begin{array}{l}\text { Useful } \\
\text { time, sec. }\end{array}$ & Kef & $\begin{array}{l}\text { Losses of } \\
1 \text { sort, sec. }\end{array}$ & $\begin{array}{l}\text { Losses of } \\
\text { 2 sort, sec. }\end{array}$ & $\begin{array}{l}\text { All } \\
\text { losses, } \\
\text { sec. }\end{array}$ & $\begin{array}{l}\text { Share of } \\
\text { losses in the } \\
\text { general } \\
\text { time, \% }\end{array}$ \\
\hline 1 & 647 & 446 & 0.69 & 68 & 133 & 201 & 31.1 \\
\hline 2 & 788 & 651 & 0.83 & 64 & 73 & 137 & 17.4 \\
\hline 3 & 1205 & 991 & 0.82 & 141 & 73 & 214 & 17.8 \\
\hline 4 & 961 & 790 & 0.82 & 75 & 96 & 171 & 17.8 \\
\hline 5 & 1181 & 878 & 0.74 & 145 & 158 & 303 & 25.7 \\
\hline
\end{tabular}




\begin{tabular}{|l|c|c|c|c|c|c|c|}
\hline 6 & 651 & 473 & 0.73 & 82 & 96 & 178 & 27.3 \\
\hline 7 & 866 & 610 & 0.70 & 92 & 164 & 256 & 29.6 \\
\hline 8 & 1017 & 780 & 0.77 & 120 & 117 & 237 & 23.3 \\
\hline
\end{tabular}

The statistical processing of the results of the observations of the process of loading showed that the average duration of loading of one unit of the transport returnable container is $28.62 \mathrm{sec}$. (table 2).

Table 2. The results of the statistical processing of time observations on the area of loading of goods in the Tyumen distribution center.

\begin{tabular}{|c|c|c|c|c|c|c|c|}
\hline \multicolumn{2}{|c|}{ interval } & \multirow[b]{2}{*}{$\mathrm{X}_{\mathrm{i}}$} & \multirow[b]{2}{*}{$\begin{array}{c}\text { amount } \\
\text { of } \\
\text { supervisions }\end{array}$} & \multicolumn{2}{|c|}{$\begin{array}{l}\text { loading transport } \\
\text { tara (TT) }\end{array}$} & \multirow[b]{2}{*}{ 莺 } & \multirow[b]{2}{*}{ 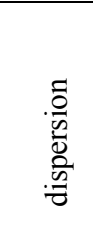 } \\
\hline 苛 & $\begin{array}{l}\dot{\bar{\Xi}} \\
\stackrel{2}{\Xi}\end{array}$ & & & duration & $\begin{array}{l}\text { average load of } \\
\text { one TT }\end{array}$ & & \\
\hline 12 & 26 & 7 & 30 & 554 & 18.5 & 0.46 & 215.64 \\
\hline 26.1 & 40 & 6.95 & 26 & 820 & 31.5 & 0.40 & 187.76 \\
\hline 40.1 & 54 & 6.95 & 5 & 234 & 46.8 & 0.08 & 36.11 \\
\hline 54.1 & 70 & 7.95 & 4 & 252 & 63 & 0.06 & 26.28 \\
\hline \multicolumn{2}{|c|}{ Total } & & 65 & 1860 & 28.62 & 1 & 465.79 \\
\hline
\end{tabular}

The logistic process of loading of goods in TDC is characterized by high intensity of work, a maximum load on the worker and it is necessary to look for other reserves of cost saving of time for operations and observance of standards for loading of goods in a transport returnable container.

\section{Conclusion}

With the growth of the competition and in connection with the increasing stream of goods, in general, it is necessary for the regional distribution center:

- to build the effective model of the organization of all logistic process on the basis of interfunctional coordination of TDC and the retail network.

- The information on quantity and condition of transport returnable container shipped from the branch stores in TDC has to be transferred online to information system of the Tyumen distribution center.

- The assembly of transport returnable container by regular working DCs or on the terms of outsourcing with hourly compensation of the collector of transport returnable container will allow to reduce the duration of the logistic process of the completion of the order at the expense of sampling in ready transport returnable container. The average value of effectiveness coefficient of the process of the completion of the order will increase from 0.76 up to 0.87 .

- The implementation of RFID technology to replace the technology of shaped coding will allow reducing the duration of the logistic process on all sites of the distribution center.

Thus, it is represented expedient to applicate the integrated logistic approach that was approved by the author in the Tyumen distribution center and the combined use of the SMED analysis, VSM that will allow to reveal problems in logistic processes in due time, and also to make operational management decisions on elimination of bottlenecks in logistic chain. 


\section{References}

1. V.V. Dybskaya, V.I. Sergeev, Logistics and Supply Chain Management 2(84), 3-12 (2018)

2. D.J. Bowersox, D.J. Closs, Logistical Management: The Integrated Supply Chain Process (Olimp-Business, Moscow, 2017)

3. http://magnit-info.ru/about/

4. E.G. Makovetskaya, N.S. Korpusopva, A.A. Gabudina, O.A. Arhipova, A theory and practice of activity of trade organizations are in the Tyumen region, Monograph (TIU, Tyumen, 2017)

5. V.V. Dybskaya, V.I. Sergeev, Logistic (Yurait, Moscow, 2019)

6. L.A. Filimonova, N.K. Skvortsova, IOP Conference Series: Materials Science and Engineering (MSE) 262, 012196 (2017) doi:10.1088/1757-899X/262/1/012196

7. E.G. Makovetskaya, E.G. Yuzikhanova, MATEC Web of Conferences 239, 04026 (2018) doi.org/10.1051/matecconf /201823904026

8. V.S. Lukinsky, A.V. Strimovskaya, Logistics and Supply Chain Management 6 (2017)

9. V.S. Lukinsky, Models and Methods of Theory of Logistic (Peter, St.P., 2007)

10. M. Imai, Gemba Kaizen: A commonsense, low-cost approach to management (Alpina P, Moscow, 2017)

11. D. Jones, J. Womack, Lean Thinking: Banish waste and create wealth in your corporation (Alpina P, Moscow, 2018) 